\title{
INDEX
}

Amin, S. See Schrader, Amin \& Brandt

Avila, M., Willis, A. P. \& Hof, B. On the transient nature of localized pipe flow turbulence, $127-136$

Balmforth, N. J. See Cawthorn \& Balmforth

Balmforth, N. J., Cawthorn, C. J. \& Craster, R. V. Contact in a viscous fluid. Part II. A compressible fluid and an elastic solid, 339-361

Bec, J., Biferale, L., Cencini, M., Lanotte, A. S. \& Toschi, F. Intermittency in the velocity distribution of heavy particles in turbulence, 527-536

Biferale, L. See Bec, Biferale, Cencini, Lanotte \& Toschi

Bonanos, A. M. See Matheou, Bonanos, Pantano \& Dimotakis

Bottaro, A. A 'receptive' boundary layer, 1-4

Bracco, A. \& McWilliams, J. C. Reynolds-number dependency in homogeneous, stationary twodimensional turbulence, $517-526$

Brandt, L. See Schrader, Amin \& Brandt

Brandt, L. K. \& Nomura, K. K. Characterization of the interactions of two unequal co-rotating vortices, 233-253

Carstensen, S. See Sumer, Jensen, Sørensen, Fredsøe, Liu \& Carstensen

Carstensen, S., Sumer, B. M. \& Fredsøe, J. Coherent structures in wave boundary layers. Part 1. Oscillatory motion, 169-206

Cawthorn, C. J. See Balmforth, Cawthorn \& Craster

Cawthorn, C. J. \& Balmforth, N. J. Contact in a viscous fluid. Part I. A falling wedge, 327-338

Cencini, M. See Bec, Biferale, Cencini, Lanotte \& Toschi

Coffey, C. J. See Hunt \& Coffey

Cooper, P. \& Hunt, G. R. The ventilated filling box containing a vertically distributed source of buoyancy, 39-58

Craster, R. V. See Balmforth, Cawthorn \& Craster

De Stefano, G. \& Vasilyev, O. V. Stochastic coherent adaptive large eddy simulation of forced isotropic turbulence, 453-470

Dimotakis, P. E. See Matheou, Bonanos, Pantano \& Dimotakis

Dixit, H. N. \& Govindarajan, R. Vortex-induced instabilities and accelerated collapse due to inertial effects of density stratification, 415-439

Eckhardt, B. See Schneider, Marinc \& Eckhardt

Elfring, G. J., Pak, O. S. \& Lauga, E. Two-dimensional flagellar synchronization in viscoelastic fluids, 505-515

Fredsøe, J. See Carstensen, Sumer \& Fredsøe

Fredsøe, J. See Sumer, Jensen, Sørensen, Fredsøe, Liu \& Carstensen

Goswami, P. S. \& Kumaran, V. Particle dynamics in a turbulent particle-gas suspension at high Stokes number. Part 1. Velocity and acceleration distributions, 59-90

Goswami, P. S. \& Kumaran, V. Particle dynamics in a turbulent particle-gas suspension at high Stokes number. Part 2. The fluctuating-force model, 91-125

Govindarajan, R. See Dixit \& Govindarajan

Hanifi, A. See Tempelmann, Hanifi \& Henningson 
Henningson, D. S. See Tempelmann, Hanifi \& Henningson

Hof, B. See Avila, Willis \& Hof

Hunt, G. R. See Cooper \& Hunt

Hunt, G. R. \& Coffey, C. J. Emptying boxes - classifying transient natural ventilation flows, $137-168$

Jensen, P. M. See Sumer, Jensen, Sørensen, Fredsøe, Liu \& Carstensen

Koch, D. L. See Raja, Subramanian \& Koch

Kumaran, V. See Goswami \& Kumaran

Kumaran, V. See Goswami \& Kumaran

Lanotte, A. See Bec, Biferale, Cencini, Lanotte \& Toschi

Lauga, E. See Elfring, Pak \& Lauga

Le Dizès, S. See Schaeffer \& Le Dizès

Liu, P. L.-F. See Sumer, Jensen, Sørensen, Fredsøe, Liu \& Carstensen

Marinc, D. See Schneider, Marinc \& Eckhardt

Matheou, G., Bonanos, A. M., Pantano, C. \& Dimotakis, P. E. Large-eddy simulation of mixing in a recirculating shear flow, 375-414

McWilliams, J. C. See Bracco \& McWilliams

Nomura, K. K. See Brandt \& Nomura

Okamura, M. Almost limiting short-crested gravity waves in deep water, 481-503

Pak, O. S. See Elfring, Pak \& Lauga

Pantano, C. See Matheou, Bonanos, Pantano \& Dimotakis

Raja, R. V., Subramanian, G. \& Koch, D. L. Inertial effects on the rheology of a dilute emulsion, 255-296

Schaeffer, N. \& Le Dizès, S. Nonlinear dynamics of the elliptic instability, 471-480

Schneider, T. M., Marinc, D. \& Eckhardt, B. Localized edge states nucleate turbulence in extended plane Couette cells, 441-451

Schrader, L.-U., Amin, S. \& Brandt, L. Transition to turbulence in the boundary layer over a smooth and rough swept plate exposed to free-stream turbulence, 297-325

Shaw, S. J. \& Spelt, P. D. M. Shock emission from collapsing gas bubbles, 363-373

Spelt, P. D. M. See Shaw \& Spelt

Subramanian, G. See Raja, Subramanian \& Koch

Sumer, B. M. See Carstensen, Sumer \& Fredsøe

Sumer, B. M., Jensen, P. M., Sørensen, L. B., Fredsøe, J., Liu, P. L.-F. \& Carstensen, S. Coherent structures in wave boundary layers. Part 2. Solitary motion, 207-231

Sørensen, L. B. See Sumer, Jensen, Sørensen, Fredsøe, Liu \& Carstensen

Tempelmann, D., Hanifi, A. \& Henningson, D. S. Spatial optimal growth in three-dimensional boundary layers, 5-37

Toschi, F. See Bec, Biferale, Cencini, Lanotte \& Toschi

Vasilyev, O. V. See De Stefano \& Vasilyev

Willis, A. P. See Avila, Willis \& Hof 


\section{ANNUAL REVIEWS}

The Essential Resource for Chemical and Biomolecular Engineering Research

Annual Reviews offers comprehensive, timely collections of critical, topical reviews written by acknowledged experts. Annual Reviews journals examine 40 focused disciplines within the Biomedical, Life, Physical, and Social Sciences. Our Editorial Committees are specialists in selecting and synthesizing literature into concise, insightful review articles. As a result, Annual Reviews journals are among the most highly cited in scientific literature and are consistently ranked within the top ten of journals for their disciplines as indexed by the ISI ${ }^{\circledR}$ Journal Citation Reports $\left(\mathrm{JCR}^{\circledR}\right)$.

\section{Annual Review of Chemical and Biomolecular Engineering}

Vol. 1 • July 2010 • Online \& In Print • http://chemeng.annualreviews.org

Editor: John M. Prausnitz, University of California, Berkeley

The Annual Review of Chemical and Biomolecular Engineering will provide a perspective on the broad field of chemical (and related) engineering. It will address advances in applied chemistry and biology, with a focus on concepts, old and new materials, and/or processes. The series will draw from disciplines as diverse as biology, physics, and engineering, with development of chemical products and processes as the unifying theme.

This journal is of direct interest to readers with a general background in the natural sciences as well as for a broad range of scientists concerned with the physical, chemical, and biological properties of materials encountered in the contemporary and future chemical industries.

\section{Access this and all Annual Reviews journals via your institution's} subscription at www.annualreviews.org

Personal copies available at a reduced rate. Institutional site license options available. Contact Annual Reviews for details. 
1 A 'receptive' boundary layer A. Bottaro

5 Spatial optimal growth in three-dimensional boundary layers D. Tempelmann, A. Hanifi \& D. S. Henningson

39 The ventilated filling box containing a vertically distributed source of buoyancy P. Cooper \& G. R. Hunt

59 Particle dynamics in a turbulent particle-gas suspension at high Stokes number. Part 1. Velocity and acceleration distributions

P. S. Goswami \& V. Kumaran

91 Particle dynamics in a turbulent particle-gas suspension at high Stokes number. Part 2. The fluctuating-force model P. S. Goswami \& V. Kumaran

127 On the transient nature of localized pipe flow turbulence M. Avila, A. P. Willis \& B. Hof

137 Emptying boxes - classifying transient natural ventilation flows G. R. Hunt \& C. J. Coffey

169 Coherent structures in wave boundary layers. Part 1. Oscillatory motion S. Carstensen, B. M. Sumer \& J. Fredsøe

207 Coherent structures in wave boundary layers. Part 2. Solitary motion B. M. Sumer, P. M. Jensen, L. B. Sørensen, J. Fredsøe, P. L.-F. Liu \& S. Carstensen

233 Characterization of the interactions of two unequal co-rotating vortices L. K. Brandt \& K. K. Nomura

255 Inertial effects on the rheology of a dilute emulsion R. V. Raja, G. Subramanian \& D. L. Koch

297 Transition to turbulence in the boundary layer over a smooth and rough swept plate exposed to free-stream turbulence

L.-U. Schrader, S. Amin \& L. Brandt

327 Contact in a viscous fluid. Part 1. A falling wedge C. J. Cawthorn \& N. J. Balmforth

339 Contact in a viscous fluid. Part 2. A compressible fluid and an elastic solid N. J. Balmforth, C. J. Cawthorn \& R. V. Craster

363 Shock emission from collapsing gas bubbles S. J. Shaw \& P. D. M. Spelt

375 Large-eddy simulation of mixing in a recirculating shear flow G. Matheou, A. M. Bonanos, C. Pantano \& P. E. Dimotakis

415 Vortex-induced instabilities and accelerated collapse due to inertial effects of density stratification H. N. Dixit \& R. Govindarajan

441 Localized edge states nucleate turbulence in extended plane Couette cells T. M. Schneider, D. Marinc \& B. Eckhardt

453 Stochastic coherent adaptive large eddy simulation of forced isotropic turbulence G. De Stefano \& O. V. Vasilyev

471 Nonlinear dynamics of the elliptic instability N. Schaeffer \& S. Le Dizès

481 Almost limiting short-crested gravity waves in deep water M. Okamura

505 Two-dimensional flagellar synchronization in viscoelastic fluids G. J. Elfring, O. S. Pak \& E. Lauga

517 Reynolds-number dependency in homogeneous, stationary two-dimensional turbulence A. Bracco \& J. C. McWilliams

527 Intermittency in the velocity distribution of heavy particles in turbulence J. Bec, L. Biferale, M. Cencini, A. S. Lanotte \& F. Toschi

537 Book Review

540 INDEX To Volume 646

Cambridge Journals Online For further information about this journal please go to the journal web site at journals.cambridge.org/flm

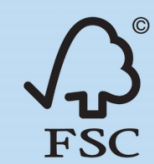

Mixed Sources

(1)

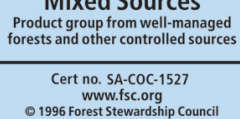

Www.fsc.org
○ 1996 Forest Stewardship Council 